\title{
THE CARBOHYDRATES OF BUFFALO AND GOAT SEMEN*
}

\author{
S. R. ANAND \\ National Dairy Research Institute, Karnal, India
}

(Received 5th Fuly 1972)

Available studies on the carbohydrates of buffalo and goat semen are limited to estimations of fructose in whole semen. In order to have a complete picture of the 'free' and 'bound' carbohydrates present, the seminal plasma of these species was subjected to 'extensive dialysis' as described by Mann \& Rottenberg (1966). The results obtained are reported in this communication.

Semen was collected by artificial vagina and the plasma was separated from the spermatozoa in a clinical centrifuge. Pooled seminal plasma (5 to $10 \mathrm{ml})$ was dialysed against distilled water with five changes for 24 to $48 \mathrm{hr}$ at $5^{\circ} \mathrm{C}$. The two fractions, dialysable and non-dialysable, were taken to the original volume of the seminal plasma at $40^{\circ} \mathrm{C}$ under vacuum. The free sugars in the dialysable fraction were estimated after deproteinization with $\mathrm{Ba}(\mathrm{OH})_{2}$ and $\mathrm{ZnSO}_{4}$ followed by deionization. The bound sugars in both the dialysable and nondialysable fractions were hydrolysed with $1 \mathrm{~N}-\mathrm{H}_{2} \mathrm{SO}_{4}$ for $6 \mathrm{hr}$ and the hydrolysed samples were deionized by passing through a column of Amberlite IR-120 $\left(\mathrm{H}^{+}\right)$and Dowex AG- $\left(\mathrm{Cl}^{-}\right)$as described by Mann \& Rottenberg (1966). Orcinolreactive compounds were estimated spectrophotometrically (Vasseur, 1948). Fructose was determined by the resorcinol method (Mann, 1946) and glucoseby glucose oxidase and horse radish peroxidase (Hugget \& Nixon, 1957). For sialic acid estimation, the samples were hydrolysed with $0 \cdot 1 \mathrm{~N}-\mathrm{H}_{2} \mathrm{SO}_{4}$ at $80^{\circ} \mathrm{C}$ for $1 \mathrm{hr}$ and the amount was estimated by the thiobarbituric acid assay method of Warren (1959). The hexoseamines were determined in the hydrolysed samples $\left(1 \mathrm{~N}-\mathrm{HCl}\right.$ for $12 \mathrm{hr}$ at 100 to $105^{\circ} \mathrm{C}$ ) by the procedure of Cessi \& Piliego (1960). The amount of total nitrogen was estimated by the micro-Kjeldahl technique.

The sugars present in the seminal fractions were separated by paper chromatography on Whatman paper No. 1, using the solvent systems, propan-1ol : ethylacetate : water (7:1:2, by vol.) (Glegg \& Eidinger, 1954) and ethylacetate : pyridine : water $(8: 2: 1$, by vol.). These were detected on paper by spraying with $\mathrm{AgNO}_{3}-\mathrm{NaOH}$ (Trevelyan, Proctor \& Harrison, 1950) and identified by co-chromatography with known samples.

The 'free' sugars in the semen of both the species consisted chiefly of fructose with small amounts of inositol (buffalo) and glucose (goat). This is in accord with the observations on human and bovine semen (Mann \& Rottenberg, 1966; Baronos, 1971b) but differs from those on boar and stallion semen (Baronos, 1971a) where inositol occurs in preference to fructose. Another

* NDRI publication no. 72-49. 


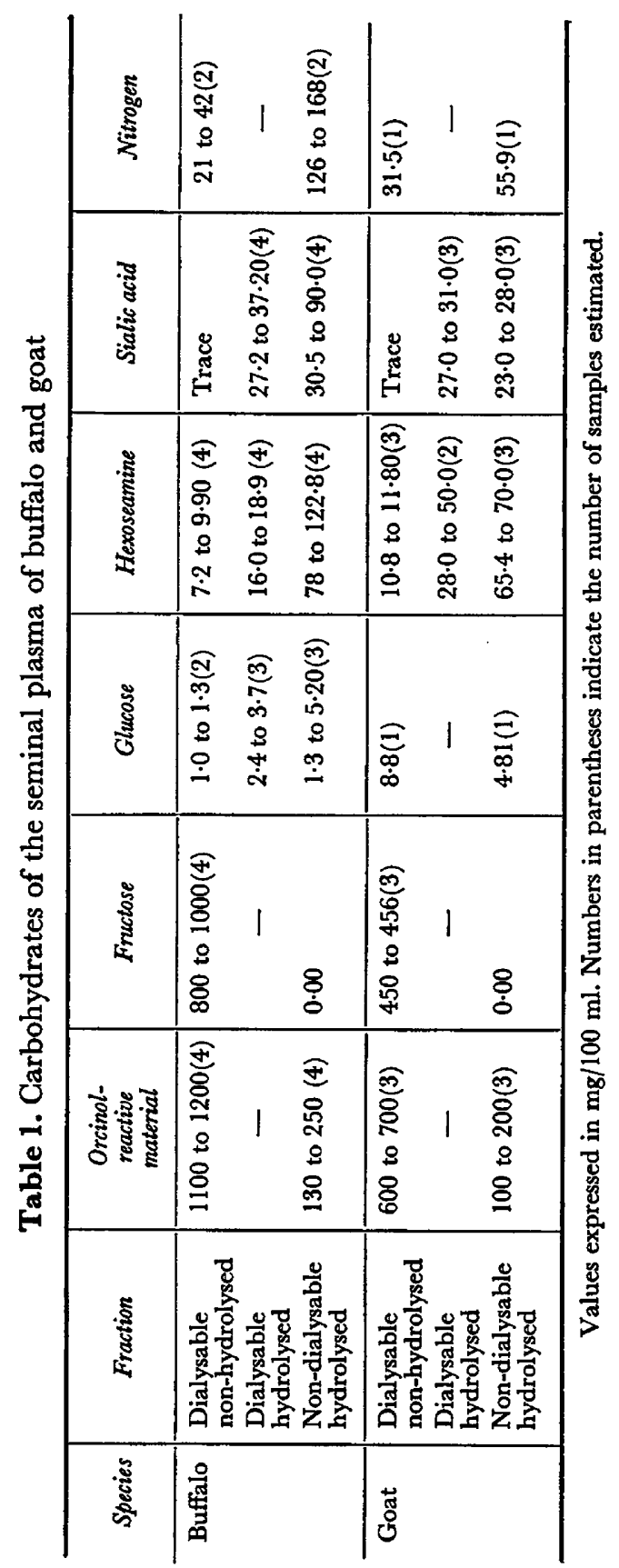


interesting feature is the occurrence of fructose at the highest concentration $(800$ to $1000 \mathrm{mg} / \mathrm{ml}$ ) in buffalo semen which also accounts for its high carbohydrate content. A part of the 'bound' carbohydrate fraction in the seminal plasma of both species occurred in the dialysable fraction. The sugars released on hydrolysis were sialic acid, hexoseamines, mannose, galactose, glucose, xylose, fucose and ribose. Here, they differ from the carbohydrate composition of human and bovine seminal plasma (Mann \& Rottenberg, 1966; Baronos, 1971b) where sialic acid and xylose were not found in the dialysed fraction and the 'bound' carbohydrates were mainly localized in the non-dialysed fraction. For buffalo and goat semen, the non-dialysed fraction was resolved by paper chromatography into four compounds; one of these was not identified while the remaining three had the same chromatographic mobility as the authentic mannose, galactose and fucose. These were eluted from the paper and their subsequent estimation by the orcinol method showed them to be in the ratio of $4: 3: 2$ for buffalo and 10:5:9 for goat. The detailed composition of both the species is given in Table 1 .

The sugars released on hydrolysis from both dialysed and non-dialysed fractions could be present as a component of a polysaccharide or in 'bound' form with protein. No evidence for the presence of polysaccharide of any sugar (mannose, glucose and galactose) was obtained when they were prepared by the procedure of alkaline hydrolysis and ethanol precipitation (Pflüger, 1903; Somogyi, 1934). Similar evidence has been obtained for human (Mann \& Rottenberg, 1966) and bovine (Baronos, 1971b) seminal plasma. Galactose constituted the major 'bound' carbohydrate of bovine, boar and stallion semen (Baronos, 1971a, b) but in both the buffalo and goat seminal plasma, mannose was present at higher concentrations than galactose. It would seem, therefore, that 'bound' carbohydrates (mannose, galactose, fucose) are present as glycoproteins with minor differences in composition for the different species. The seminal vesicles were shown to be the source of fructose and 'bound' carbohydrates containing galactose in bovine seminal plasma (Baronos, 1971b).

The author is grateful to the director, Dr D. Sundaresan, for encouragement. The technical assistance of Mr Ratten Singh is gratefully acknowledged.

\section{REFERENCES}

Baronos, S. (1971a) Seminal carbohydrate in boar and stallion. F. Reprod. Fert. 24, 303.

BARONOS, S. (1971b) The bound carbohydrate of bovine seminal plasma. F. Reprod. Fert. 25, 219.

Cessi, C. \& Pilrego, F. (1960) The determination of amino sugar in the presence of amino acids and glucose. Biochem. 7. 77, 508.

GlegG, R. E. \& EIDINGER, D. (1954) Hydrolysis of polysaccharides by a cation exchange resin and identification of monosaccharide components by paper chromatography. Analyt. Chem. 26, 1365.

Huggett, A. St.G. \& Nixon, D. A. (1957) Enzymatic determination of blood glucose. Biochem. 7. 66, $12 \mathrm{P}$.

MANN, T. (1946) Studies of the metabolism of semen. 3. Fructose as a normal constituent of seminal plasma. Site of formation and function in semen. Biochem. F. 40, 481 .

MANN, T. \& RotTENBERG, D. A. (1966) The carbohydrate of human semen. F. Endocr. 34, 257.

PrLüGer, E. (1903) Über den Glykogengehalt der There in Hungerzustand. Pflügers Arch. ges. Physiol, 91, 119. 
SoмоGy, M. (1934) The solubility and preparation of phosphorus and nitrogen free glycogen. F. biol. Chem. 104, 245.

Trevelyan, W. E., Proctor, D. P. \& Harrison, J. S. (1950) Detection of sugars on paper chromatograms. Nature, Lond. 166, 444.

VASSEUR, E. (1948) A spectrophotometric study on the orcinol reaction with carbohydrates. Acta chem. scand. 2, 693.

WARren, L. (1959) Sialic acid in the human semen and in the male genital tract. F. biol. Chem. 234, 1971. 